\title{
Effective Communication And Creating Professional Learning Communities Is A Valuable Practice For Superintendents
}

Ann Toler Hilliard, Bowie State University, USA

Edward Newsome, Jr., Bowie State University, USA

\begin{abstract}
As the chief executive officer, the superintendent must demonstrate high quality performance at every level in order to impact student achievement. In order to be an effective superintendent, the individual must have knowledge and skills in educational leadership and be able to articulate information clearly and precisely about the school district, state and federal accountability systems, policy related to student achievement and personnel practices. The American Association of School Administrators states that the superintendent must know policy for collective bargaining processes for the state/local schools, school district policy and administrative regulations, district finances and budget matters, model the use of technology for instruction and management and should know the role of the Board of Education (AASA, 2011).
\end{abstract}

Superintendents do not work alone, but work in collaboration with school personnel, leadership teams, broader communities and the Board of Education to ensure a productive school system. The responsibilities of the superintendent are many. The superintendent has the task to supervise the general conduct of district schools, instructional curriculum, handle school district management affairs, hiring appropriate personnel and dismissal of personnel based on state policy through the human resources management office. For the local schools, the superintendent should seek ways to encourage the practices of learning communities within the school district for the purpose of working together to improve teaching instructional skills based on the needs of students and if effective will promote higher student learning (Stoll, 2006). This study will focus on skills and knowledge needed for superintendents, what parents want, value of data, strategic planning, effective communication, learning community practices of ethics and morals, technology as a resource, and the characteristics of high performing schools.

Keywords: Role of the Superintendent; Effective Communication; Learning Communities

\section{INTRODUCTION}

O)

uperintendents must hold national or state certification and the certification must be current. All superintendents must demonstrate high knowledge and skills in teaching and learning, leadership, technology and management that promotes student achievement. Using the business model, some superintendents are hired who may not have been a teacher, principal or district level individual in the field of education. When such individuals are hired by a school district the title given may be chancellor (Bjork \& Kowalski, 2005). The superintendent must secure and use appropriate and needed resources that are human and non-human for schools within the district timely. Superintendents must review data trends and talk with stakeholders within the school district in order to make appropriate decisions when planning the strategic plan for improving schools. The effective superintendent will work with the Board of Education and school leaders and teacher leadership organizations to ensure that the thoughts of many are heard and possibly considered within the goals of the strategic plan. The strategic plan and all expectations should be written in language that is easy to understand by all stakeholders. The measurable outcomes of the strategic plan's goals and objectives should be reviewed annually to see if the goals and objectives were met, if not, why not (Maki, 2001). 
The effective superintendent must hold self and other stakeholders accountable in order to promote higher student achievement. The superintendent and the leadership team for the school district must keep in mind that there is a need for schools to use high standards and to use proven research-based practices to make it happen for school improvement. The superintendent must demonstrate through action by being a strong supporter of student achievement that is for all students (Portis \& Garcia, 2007). Parents of students at the high and low spectrum must see the superintendent as an individual who truly supports appropriate instructional services in meeting the needs of all students regardless of ability (Marzano, 2006).

\section{WHO IS THE SUPERINTENDENT AND WHAT THE SUPERINTENDENT NEEDS TO KNOW?}

The superintendent is the chief executive officer for the school district or school system. The superintendent has many responsibilities including collaboration in decision-making and sharing information with the Board of Education and other stakeholders. Some of the key responsibilities that superintendents have are to clearly articulate the district's vision, mission, core values, goals, school policies, laws and expectations/regulations relating to schools within the district. In the area of supervision, the superintendent is responsible for supervising building school leaders and others who work in central administration. The superintendent oversees the district's curriculum, management of business matters, working with human resources office personnel for the hiring and firing of personnel based on policy (Bass, 2008).

The preparation of the superintendent is most common as an individual who has experience as a classroom teacher, counselor, assistant principal, principal, district/region/cluster supervisor, assistant superintendent, community superintendent or vice superintendent. However, within the past ten years in some urban districts in particularly, individuals have been appointed as superintendents who have had non-school based experiences, but rather from private sector organizations or the business community and are often called chancellor (Fusarelli \& Fusarelli, 2005).

The superintendent needs to be competent with knowledge regarding state and federal accountability systems and expectations related to student achievement and personnel practices. The superintendent must know state laws and policies regarding the collective bargaining process, school district policy and administrative regulations, district finances and budget matters. Serving as a competent individual for 21 century practices, the superintendent must know how to use technology for instruction and management. Politically, the superintendent must have an effective working relationship with the Board of Education and the broader community (Carter \& Cunningham, 1997).

\section{SUPERINTENDENTS NEED TO KNOW WHAT PARENTS WANT}

Parents, children and guardians are key stakeholders within the school district. The chief officer as superintendent should know what parents expect or want from the school district. Based on a survey conducted by the National School Public Relations Association, a high percentage of parents have concerns about school safety, quality education for their children and diverse communication means from the school district. A survey was conducted from 22 states including rural, small and large urban districts and found from the findings of 43,310 responses, the major concern from parents and non-parents in the survey was that the superintendent should ensure that the school district improves its communication with parents by using available technology such as: online parent portal, emails, newsletters/announcements, school district websites and voice messaging system directly to parents. Parents completing the survey responses stated that it is important to receive current updates from the school district regarding: curriculum, progress of their child timely, syllabi that articulates course contents and requirements, homework, instructional teaching methods, quality of teaching, testing expectations and the grading policy, student safety issues especially on bullying and disciplinary actions based on policy and a calendar of events for the academic year were all important to parents. The benefit or value of the NSPRA survey would give the superintendent, principals and teachers in the school district information from parents that says there is a need to improve their communication to parents in a more relevant and timely manner (Mapp, 2003). 


\section{VALUE OF DATA}

An assessment is needed for the school district before proper planning can take place. The superintendent with a collaborative team within the school district should look at the school district's (SWOTs) strengths, weaknesses, opportunities and treats before composing a strategic plan for improving the school district. Data gathered from assessment documents and input from stakeholders should be used to drive decision-making for the superintendent's school district team members. Since teachers are the closest individuals to the delivery of instructional services to students, the superintendent should have teachers represented on the strategic plan for the district (Honawar, 2008). Members of the strategic plan team should join the broader teams in local schools later to lead activities related to the superintendent's learning community's efforts. In order for all stakeholders to be on the same page with the understanding what it will take to improve student achievement, the superintendent with collaboration from leadership teams can implement best practices for learning communities. School districts that improve student learning have more of a practicing model of learning communities in place (Schmoker, 2004). This can be debatable like most statements. However, according to (DuFour, 2004) the whole concept of collaborative team members using the learning community model has proven to help schools to improve their communication, teaching efforts and provides improved services to students.

\section{STRATEGIC PLANNING}

As the superintendent of a school district, it is essential to have a smart strategic plan. The smart plan will address the direction in which the superintendent plans to take the school district with the support of the leadership team. The basic guidelines for strategic planning must be specific, measurable, acceptable, realistic, time-sensitive, extending, rewarding, accountable and evaluative by all stakeholders (Baldrige, 2004). A specific strategic plan:

1. Processes to establish priorities on what will be or intended to be accomplished in the future.

2. Focuses on choices related to what the superintendent will do and what the superintendent will not do.

3. Pulls the entire organization together around a single game plan for execution i.e. student achievement in reading and/or mathematics.

4. Gives a broad outline on where resources will be allocated based on the needs of schools within the school district.

A strategic plan is important, because it forces the superintendent and stakeholders to be proactive about the future of the school district. Strategic planning improves organizational performance. The plan helps to counter excessive inward and short-term thinking, but gives a clear focus for solving major problems and addressing issues at a macro level with the organization. Finally, the strategic plan communicates to all stakeholders as to what is important for the school district. Planning and executing a plan is important; however, it is essential too, that feedback is given by stakeholders to the superintendent for the purpose of improving the strategic plan (APQC, 1999). These are some of the major reasons for having a venue for feedback regarding the strategic plan is important, because it:

1. Helps to align information from the top to create a strategic management system.

2. Uses a balanced scorecard framework to organize the report actionable components.

3. Uses the scorecard for managing the execution of district strategy.

4. Helps to look at different perspectives and takes into account cause-effect relationship (lead and lag indicators).

5. Establishes a regular review cycle of information within the strategic plan.

6. Analyzes and compare trends using graphs for rapid communication of performance related to (inputs to outputs to outcomes).

7. Works in reverse to upstream to revise the plan if applicable: Action Plans, Operating Plan and Strategic Plans.

8. Recognizes and celebrates good performance results and acknowledging those results plus brainstorms and charges to take corrective action on poor performance results not blaming anyone, but seeking ways to fix problems within the school district. 
To have a strategic plan is essential as stated; however, a plan cannot be executed if the plan does not have adequate resources included in the budget. The resources that are needed to execute the strategic plan are competent humans, money, time, appropriate facilities and other key resources plus this is a responsibility of the superintendent working with the Board of Education to provide needed resources to schools. By aligning the needed resources to schools equitably can help to validate and initiative a viable action plan for the school district. The action plan should include specific goals and objectives, time-lines, responsible persons, implementation time and expected outcomes (O’Neill \& Conzemius).

The superintendent has the responsibility to ensure that the strategic plan is communicated clearly and briefly to all stakeholders including the public. The communication aspect of the strategic plan should state how the organization or school district wants to be perceived in the future. The strategic plan will state what success looks like, an expression of the desires and state of the organization. The strategic plan challenges everyone to reach for something significant - inspires a compelling future, and provides a long-term focus for the entire organization or school district. The strategic plan explains the basic elements that need to be fulfilled, expresses the core values of the organization/school district and describes a future end-state or a desired outcome that is supportive of the mission and vision of the school district. As an overview, the superintendent should be able to communicate where the school district is at this time, where does the district need to be and how the school district collaboratively will close the achievement gap and how progress will be monitored and evaluated (Reeves, 2007).

\section{EFFECTIVE SUPERINTENDENTS MUST HAVE EXCELLENT COMMUNICATION SKILLS}

The time on the job for most superintendents may last from three to five years on an average. For example: Forty-three percent of superintendents in the State of California districts in a study conducted by American Education Research Journal found that 90 percent of 100 districts had superintendents to leave the profession as a superintendent within three years. If this is an indicator for the staying time of a superintendent, many school districts do not have longevity built within the system for long term "stay in the position" for superintendents. Based on research conducted by Vanderbilt University, districts with a student enrollment of less than 29,000, the superintendent has greater than a 50-50 chance of staying in the job for nearly three years compared to large school districts. In larger school districts, the superintendent's turnover rate is about 70 percent for a three year period (Sparks, 2012). However, within that time of three years, the superintendent must demonstrate performance at a high level. The most successful superintendents have been noted for much strength in their leadership capacity based on effective communication. However, the key factor that has added to the superintendent's strengths and is highly noted is effective communication to all stakeholders in a clear and precise manner. A highly respected former superintendent, Dr. Jerry Weast, of Montgomery County, Maryland stated that "great communication skills will add years to your tenure as a successful superintendent." Therefore, effective communication must be a priority not a forgotten thought for great superintendents. Superintendents of school districts must also ensure that members of their leadership team are great communicators too. The superintendent must establish and maintain a culture of effective communication intentionally in all schools. A rule of thumb, a great superintendent should stay focused on district priorities and not become psychologically impaired by negative gossip within the district (Bagin, 2012).

Being an effective communicator, the superintendent must have the ability to be able to:

1. Articulate the needs of the school district by looking at data and interacting with the community. Based on data collected, the school district's strengths, weaknesses, opportunities and threats should be examined by the superintendent and team members in order to prepare an appropriate collaborative strategic plan of action in meeting the academic, social and cultural needs of students.

2. Establish and articulate the school district's vision and mission using a collaborative approach and to articulate a clear vision and mission to the public using correct/easy language to interpret in the school district's strategic plan.

3. Articulate knowledge of national common core standards and the curriculum.

4. Create a positive learning environment for all schools in the district by providing human and non-human resources in an equitable manner.

5. Communicate ways to build census among school educators and the community.

6. Promote the value of learning communities for school leaders. 
Again, the superintendent must be able to clearly articulate a vision and mission for the school district to all stakeholders. Stakeholders include the Board of Education, vice/assistant/associate superintendents, directors/coordinators of district programs, principals, assistant principals, classroom teachers, resource teachers, students, parents/guardians, others and the community (Weast, 2008). The superintendent must be able to meet the needs of schools based on varied data reports (quantitative and qualitative). The effective superintendent establishes a collaborative team from the beginning to work toward priority needs of the school district by using a typical learning community model to make an impact on student achievement (Mason, 2003). If students are not achieving in a satisfactory manner, this is a reflection on the non-effectiveness of the superintendent as the chief officer of the school district and other service providers to students. No, the superintendent does not work alone, but it is the responsibility of the superintendent to put needed resources in place for schools and monitor what is going on in schools to ensure student success. Yes, this is a big charge, but the achievement of students is a collaborative effort of all stakeholders within the school district. The superintendent is hired by the Board of Education to improve school performance within the school district.

When communicating to the public, the superintendent must know the culture of the school district and be able to share a clear vision with all stakeholders within the culture (Sergiovanni, 1990). The superintendent must demonstrate being an instructional leader, excellent communicator, effective manager, not afraid to be a risk taker for the good of the school district and show flexibility when appropriate. The most successful superintendent knows that that is important in order to solicit input from key stakeholders within the school district and community before making final decisions about district school matters. For example, if stakeholders placed a focus on the equity of high achieving students in the school district because these students who are the best and the brightest and these students are being neglected in schools, what plan would the superintendent use to address this concern for high achieving students (Siccone, 2011)? In essence, the superintendent has to have and implement a plan of success for all students in the school district for students who perform at a high and low level.

Using a conceptual framework, an effective superintendent works closely with members of the Board of Education and other stakeholders as illustrated in Figure 1.

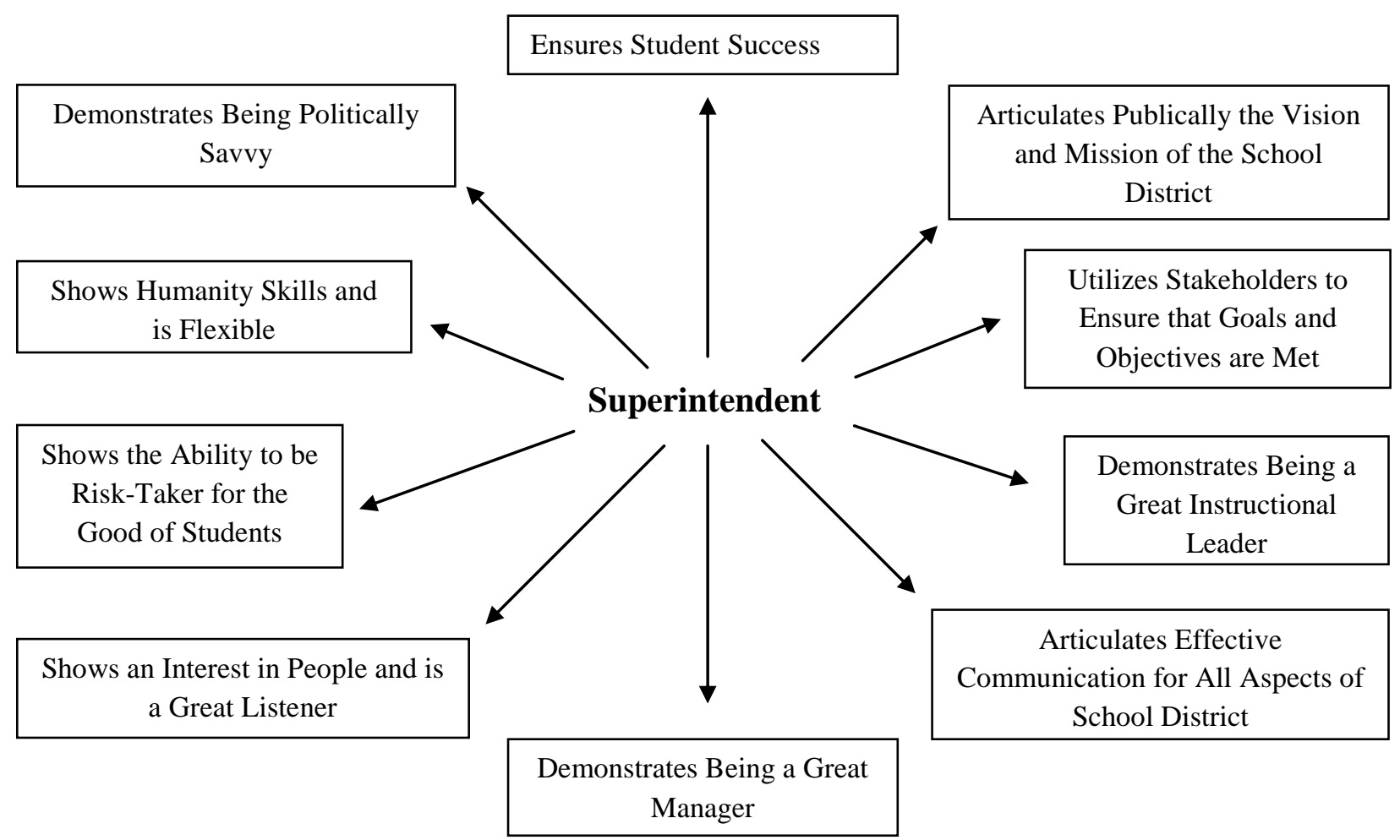

Figure 1: Effective Communicator: Works with BOE to Establish the Vision and Mission of the District School Note: Figure X. http://www.greatscools.orga/improvement/quality-teaching/94-what-makes-a-great-superintendent 


\section{WHAT IS A PROFESSIONAL LEARNING COMMUNITY?}

As stated, the superintendent does not work alone. Therefore, the most effective superintendents are wise enough to create leadership teams and promote a school district environment of learning communities. When teachers, school leaders and others come together in the school community to solve problems so that curriculum and learning tasks can be enhanced for students; or engaging students, teachers, and leaders simultaneously in learning is a common definition for the professional learning community (McLaughlin \& Talbert, 2010).

Based on Dufour's observations, who once served as superintendent in Chicago, the learning community concept and practices have helped superintendents to be more effective or one could say where successful reforms took place in school communities, professional learning community practices were value added to student achievement. Using interdisciplinary teams in each school, school teams were introduced to the professional learning community concept and the Board of Education members attended the training too and supported the practice of learning communities. Professional learning communities have many benefits by helping all stakeholders to work together to solve issues or concerns within the teaching and learning environment within school districts have proven to be a key quality of learning community practices. The professional learning community can help teachers gain an improved understanding of teaching practices as well as a personal knowledge about who they are and the crucial roles teachers play as educators in schools. The main outcome objective of the concept of the learning community is having individuals to work together to improve student achievement (Dufour, 2004).

Stakeholders must work together in order to create a viable learning community for promoting higher student achievement. Learning communities improve the communication and function of an organization. Some common characteristics of a collaborative learning community are as follows:

1. $\quad$ Articulates a Shared Vision, Values and Mission

2. $\quad$ Engages Stakeholders in Shared Leadership Activities

3. Makes Decisions Based on Data and Research

4. $\quad$ Participants in Teaching, Learning and Leading

5. Shares Instructional and Management Practices

6. Supports the Collaborative Learning Community Concept

7. Uses Technology to Communicate to the Larger Community

Within the professional learning communities the participants must work together to ensure the success for all students. In order to continue to improve the practices within the learning communities for the school district, the stakeholders and participants must look at solution driven ways to improve instruction in schools by increasing the support of teachers, counselors, students and administrators through continuous professional development training face-to-face, blended learning and/or online. The superintendent must provide the needed resources for improving the skills and knowledge of school stakeholders and services given must be monitored for their effectiveness. The superintendent's leadership team should have frequent contact and visibility within schools in the district to ensure that lesson plans, objectives and formative assessment activities are being implemented by teachers that will impact student achievement in a positive manner (Gamble, 2008).

\section{PROFESSIONAL LEARNING COMMUNITIES MUST HAVE ETHICS AND MORALS}

The professional learning community participants must demonstrate good ethics which represent a committed obligation for promoting high student achievement. All team leaders in the professional learning community should continue to practice excellent morals toward each other and students, because it is what parents expects from those individuals who have been entrusted to provide their children with a quality education. Good morals and ethics should be the practice of all school district personnel (Bryk, 2002).

As the leader of the school district, the superintendent should hold self and all school personnel accountable for their actions in reference to the achievement of students. Good ethics and morals toward all students must be the expectation within the school district. The professional learning community has an obligation to ensure the success 
of all students. Members of professional learning communities within the school district should look at what has seemingly been successful practices within the school district and emulate those practices (Dufour, Eaker, 2010).

In understanding professional learning communities, educators must also look at the history of what has been effective in obtaining student achievement. By looking at the past, educators are able to better chart their path toward the future. Along with looking at the past, professional school communities need to frequently reference the vision that the school system is attempting to bring to realization (Kritsonis, 2008).

The whole essence of the professional learning community is to work together collaboratively to advance the priority goals and objectives of the school district. The benefits of learning communities include focused discussions and actions on teaching and learning, participants have less fear of not knowing but having the interest to seek new and improved knowledge for instruction. The professional learning community should ensure that the curriculum is research-based and practices put in place to promote the achievement of all students (Hoy, 2009). Fidelity must be given to an informational-driven curriculum that meets the specific needs of students. The focus of the learning community should be developed into a culture where all stakeholders demonstrate practical ways to move students, as well as faculty, into truly becoming lifelong learners (Gamble, 2007).

\section{TECHNOLOGY IS A NEEDED RESOURCES}

Twenty First Century school districts must be current in the use of various technologies for instruction and management. Technology is used to enhance teaching, learning and management. The superintendent could work in a rural or urban district, it is still necessary that technology resources are available for teachers, students and educational leaders at all levels and professional development workshops should be made available so that school personnel and students are competent and comfortable in using various types of technology. The superintendent must be aware that it is necessary for students today to have access in working with current technologies in order to be competitive in the marketplace. All superintendents need to continue to keep their technology skills sharpen too, so that they can model expectations to others within their district. Plus the superintendent must ensure that equity of technology and technology training opportunities are offered in all schools for teachers, students and school leaders, because too many senior faculty and staff may not feel comfortable with their skills and knowledge level using technology. According to Keith R. Krueger, too many superintendents do not embrace technology as their job, because some superintendents see technology leadership is for the technology officer to talk about and execute. In order to be viewed as a competent individual using technology, the superintendent needs to show interest and competence in using various technology tools. Technology will continue to be an expectation and natural way of operation in school districts by using various types of technology tools naturally (AASA, 2012).

Technology is important in schools, because schools need real-time information to stay current. Globally, change is quick and inclusive if schools are ready to move forward. Today, teachers and students need relevant and correct information and reference sources to identify the origin of information. Therefore, technology engagement will afford teachers, students and school leaders to have the competitive edge that is needed to succeed in the technologically-driven society. By providing appropriate and needed technology for schools, the superintendent can help to ensure proper implementation and assessment of curriculum and many other aspects for the school district as it grows in quality of services. It is essential that the superintendent provide all schools in the district with the needed common core standards for curriculum and assessment resources to promote higher student achievement (Stringfield, Wayman \& Yakimowski, 2005). Just to name a few, these are some of the common technology tools that the superintendent could provide for teachers to enhance their teaching and learning skills.

1. Apple iPad - allows the teacher and students to use with capabilities as a regular computer.

2. Aviary - makes it easy to edit images and use in music and audio to change screen captures.

3. Evernote - helps to capture great ideas, photos, recordings, or just about anything else that could be used in many subjects.

4. Dropbox - helps to store, share collaboratively and gain access to various types of data.

5. Diigo - allows the user to highlight bookmarker information and make notes on the electronic page.

6. Google Earth - helps the geography teachers to share how students can do projects and how the geological process works. This technology tool can help students and teachers to connect with others globally and become partners and supporters of special projects. 
7. Internet Resources - offers a number of great educational technology resources and information for teachers, i.e. email, videos, lesson planning information and professional development and useful educational resources.

8. Jing - helps teacher and students to take screenshots as images and make videos for three or more minutes plus the user can edit the video and share the improve the looks of the video for audience to review.

9. SlideShare - allows teachers and students to present documents, power points and videos to share with others and in return others may share their documents too.

10. YouTube - video-sharing website on which users can upload, share, and view videos.

Most school districts have access to a variety of technology software similar to many of the items broached above for instruction and managerial matters. Today, it is crucial to enhance the delivery of services for instruction and management in a more productive and time-sensitive manner (Zhao, Frank, 2003).

\section{CHARACTERISTICS OF HIGH PERFORMING SCHOOLS}

When it is all said and done, the outcome performance of schools is expected to be effective. The public is expecting for schools to be successful and the public looks to the superintendent to make it happen by the performance of instructional and leadership teams in the school district. Again, the superintendent is changed with a high order of having high performing schools. In order to have high performing schools, there are some common characteristics that have been reviewed time and time again for positive results (Baker, Herman \& Bain, 2009). Based on research these are common characteristics of high performing schools: clear and shared focus, high standards and expectations for all students with no exception, effective school leadership, high levels of collaboration and communication, appropriate curriculum, instruction and assessments aligned with state standards, frequent monitoring of learning and teaching, focused differentiated professional development based on the needs of teachers, staff and school leaders, supportive learning environments, high level of family and community involvement. If the common characteristics are in place and expectations have been met, school districts have a better chance of obtaining a high performing school record (Bulach, Lunenburg \& Potter, 2008). These common characteristics of high performing schools are similar to what was stated by early successful schools as follows: communicate a clear school district mission, articulate high expectations for success, strong instructional leadership through action, time sensitive monitoring of students' progress, time provided for teaching and learning and students performance, the school's environment should be safe and orderly, and relationship building with school personnel and parents must also being a top priority (Darling-Hammond, 1997).

\section{CONCLUSION}

The superintendent has a responsibility to dialogue with stakeholders within the school district to discuss and collaboratively plan strategic ways to improve the skills, knowledge and talents of all students within the district. Superintendents should provide the opportunity for school administrators/leaders, teachers and staff to participant in professional growth activities that promote the formation and us of professional learning communities across the school district that is designed to promote ways to improve instruction for student learning. The superintendent should effectively communicate the needs and how to meet those needs for improved teaching, learning and leading in all schools. The superintendent with a team of stakeholders should use quantitative and qualitative data to determine the strengths and needs of schools; thereafter, to establish a strategic plan of action to address the specific needs. The strategic plan for the school district should be specific, measurable, acceptable, realistic, time-sensitive, extending, rewarding, accountable and evaluative for quality assurance. The strategic planning is imperative for the superintendent and school leaders to acquire gains in student achievement. The superintendent along with school leaders should embrace the importance of strategy by developing plans that are focused on educational experiences that provide consistent monitoring and evaluations for school district improvement (Cook, 2001).

It is necessary too, that the superintendent model high expectations, motive stakeholders and support the establishment of professional learning communities with needed school resources i.e. technology, adequate personnel, facilities and support from community resources for school programs of learners and leaders who plan and implement strategies that improve teaching skills that promote higher student achievement. Learning 
communities are most successful when stakeholders share educational values, vision, leadership and management collectively for student learning. Learning communities must continue to reflect on their practices, collaborate and focus on teaching and learning and promote collective professional learning (Reeves, 2007).

At the end of the academic year, the superintendent must participate in a self-evaluation and then be evaluated by members of the Board of Education based on goals and objectives set collaboratively between the Board of Education and the Superintendent. The question must be asked were the goals and objectives met for the academic year as intended. If the superintendent is reappointed by the Board, the superintendent must commit to an effort of continuous improvement for the school district. The superintendent is accountable for improvement of the school district. The improvement must be evident by an increase in student achievement and other improvements needed within the school district (Waters \& Marzano, 2007).

\section{AUTHOR INFORMATION}

Dr. Ann Toler Hilliard is an assistant professor who teaches in the Department of Educational Studies and Leadership at Bowie State University, U.S.A. The author teaches classes related to educational leadership policy issues, planning and evaluating, human resources, and dissertation one/two; group dynamics and human relations. The author's research focus is instructional leadership, learning communities, professional development, teaching and learning, blended learning and international studies. The author coordinates activities that provide professional experiences for graduate candidates who are seeking the opportunity to serve as school administrators at the building and district level. Education: Ed.D., George Washington University, M.S. Johns Hopkins University, M.A.T. Trinity University-Washington, B.S. Elizabeth City State University and Certificate for Consulting, Harvard University. E-mail: draph1@juno.com (Corresponding author)

Dr. Edward Newsome, Jr. is an adjunct professor who teaches in the Department of Educational Studies and Leadership at Bowie State University, U.S.A. Dr. Newsome, the author, has served at the senior executive level in some of the top performing school districts in America. His experiences include quality years of service to children and adults as an administrator, leader, teacher, and special educator. During his professional career he has developed technical and career centered programs and designed educational networks that were aimed at guaranteeing success for youngsters in a $21^{\text {st }}$ Century global society. He is committed to impacting the world by developing leaders that will engage the $21^{\text {st }}$ Century social and global economy. Education: Ed.D. Nova Southeastern University, M.S. Bowie State University, B.S. Elizabeth City State University and Certificate for Professional Educator’s Leadership Program, Harvard University. E-mail: ednewso@yahoo.com

\section{REFERENCES}

1. American Association of School Administrators. Washington, D.C. 2011-2012.

2. American Productivity and Quality Center (1999). Strategic Planning: What Works and What Doesn't.

3. Bagin, Rich (2012) Educational Research Service Board of Directors and a board member of the Learning First Alliance (LFA).

4. Baker, E., Herman, J., \& Bain, J. What makes a good school? A guide for parents seeking excellence in education. Cresst, 1-11. Retrieved February 9, 2009.

5. Baldrige National Quality Program (2004). Education Criteria for Performance Excellence.

6. $\quad$ Bass, B., \& Bass, R. (2008). The Handbook of leadership: Theory, research and managerial applications. New York, NY: The Free Press, Simon and Schuster.

7. Bonstingl, J. (2009, January). Strategic planning throughout tough times. Leadership, 38(three), 8-10. Retrieved July 8, 2009, from Academic Search Complete database.

8. Bjork, L. G., \& Kowalski, T. J. (Eds) (2005). The contemporary superintendent: Preparation, practice, and development. thousand Oaks, CA: Corwin Press.

9. Bryk, A.S., \& Schneider, B. (2002). Trust in schools: A core resource for improvement. New York: Russell Sage Foundation.

10. Bulach, C., Lunenburg, F. C., \& Potter (2008). Creating Culture of High-performing schools: A comprehensive approach to school reform. Lanham, MD: Rowman \& Littlefield. 
11. Carter, G. R., \& Cunningham, W. G. (1997) The American school superintendent: Leading in an age of pressures. San Francisco: Jossey-Bass.

12. Conzemius, A. and O’Neill, J., 2002, The Handbook for SMART School Teams. Solution Tree, Bloomington, IN.

13. Cook, W.J. (2001). Strategic Planning for America's Schools. The Cambridge Group, Revised Edition V, 2001.

14. Darling-Hammond, L. (1997). The Right to Learn: A Blueprint for Creating Schools that Work. San Francisco: Jossey-Bass, Inc.

15. DuFour, R. (2004, Might). What is a Professional Learning Community? Educational Leadership, 61(6), 6. Retrieved July 7, 2009, from MAS Ultra - School Edition database.

16. DuFour, R., Eaker, R. \& DuFour, R. (2006). On common ground: The power of professional learning communities. Bloomington, IN: Solution Tree.

17. Dufour, R., Eaker, R. \& Many, T. (2010) Learning by doing (2nd.). [Kindle DX version]. Retrieved from www.Amazon.com

18. Fusarelli, B. \& Fusarelli, L. (2005). Re-conceptualizing the superintendency: Superintendents as social scientists and social activists. In L. G. Bjork \& T. J. Kowalski (Eds.), the contemporary superintendent: Preparation, practice, and development (pp.17-206). Thousand Oaks, CA: Corwin Press.

19. Gamble, J. (2008, March). Professional studying communities. School Library Media Activities Monthly, 24(7), 17-17. Retrieved July 8, 2009, from MasterFILE Premier database.

20. Honawar, V. (2008, April 2). Working smarter by working together. Education Week, 27(31), 25-27. Retrieved July 8, 2009, from MasterFILE Premier database.

21. Hord, S. M., \& Sommers, W.A. (2008). Leading professional learning communities: Voices from research and practice. Thousand Oaks, A: Corwin Press.

22. Hoy, A. W., \& How, W.K. (2006). Instructional leadership: A research-based guide to learning in schools $\left(3^{\text {rd }}\right.$.ed.). Boston, MA: Pearson Education.

23. http://www.greatscools.orga/improvement/quality-teaching/94-what-makes-a-great-superintendent

24. Kritsonis, W. (2007). Techniques of knowing through the realms of meaning. Houston, TX: National FORUM Journals.

25. Kaufman R., Herman J., \& Watters K. (2002) Educational planning: Strategic, tactical, and operational. Lanham, MD Scarecrow Press.

26. Kohn, A. (1999). The schools our children deserve (pp. 26-28). New York: Houghton Mifflin Company.

27. Kraut, H. (2000). Teaching and the art of successful classroom management: A how-to guidebook for secondary schools (3rd ed.). Staten Island: Aysa Publishing, Inc.

28. Karen L. Mapp, "Having Their Say: Parents Describe How and Why They Are Involved in Their Children's Education," School Community Journal 13, no. 1 2003, 35-64.

29. Maki, P. (March, 2001). Student outcomes assessment: Strategies for getting started, sustaining the momentum, and addressing obstacles. AAHE National Conference on Higher Education, Washington D.C.

30. Mason, S.A. (2003, April). Learning from data: The role of professional learning communities. American Educational Research Association, Chicago, IL.

31. Marzano, R. J. \& Waters, T. (2010). District Leadership that Works: Striking the right balance. Bloomington, IN; Solution Tree.

32. McLaughlin, M. W. and J. E. Talbert, "Professional learning communities: Building blocks for school culture and student learning." Voices in Urban Education (VUE), Spring, 2010.

33. Milian, Mark (February 19, 2009). "YouTube looks out for content owners, disables video ripping" http:// latimesblogs. latimes. com/technology/2009/ 02/ ---mark-milian. html?cid=149000259. Los Angeles Times. Retrieved February 21, 2009.

34. Minneapolis Public School District (2010) Minneapolis public schools 2007-2012 strategic plan

35. National School Public Relations Association, 2012.

36. Ninan, M. (2006). School climate and its impact on school effectiveness: a case study, 1-14. Retrieved February 6, 2009, from http://www.leadership.fau.edu/icsei2006/Papers/Ninan.pdf

37. Patten, C. B. (2003). What makes a good teacher. Retrieved February 8, 2009 from Cui.

38. Reeves, D. B. (2004). Accountability in action: A blueprint for learning organizations. Englewood, CO: Advanced Learning Press. 
39. Sadker, D. M., \& Zittleman, K. R. (2007). What makes a school effective?

http://www.education.com/reference/article/Ref_What_Makes_School/. Retrieved February 8, 2009, from Google.

40. Sergiovnni, T. J. (1989). Leadership as cultural expression. Classic readings in organizational behavior (335-343), J. Steven Ott (Ed.). Pacific Grove, CA: Brooks/Cole.

41. Siccone, F. (2011). Essential skills for effective school leadership. San Francisco, CA: Allyn \& Bacon.

42. Stoll, L, Bolam, R., \& McMahon, (2006) Professional learning communities: Source materials for school leaders and other leaders of professional learning communities. London: Innovation Unit, DfES, NCSL and GTC.

43. Stringfield, S., Wayman, J. C., \& Yakimowski, M. (2005). Scaling up date use in classrooms, schools and districts. In Dede, C., Honan, J. P. \& Peters, L. C. (eds.), Scaling up success: Lesson learned from technology-based education innovation. San Francisco: Jossey-Bass.

44. Waters, J. T., \& Marzano, R. J. (2007). The primacy of superintendent leadership. School Administrator, 64, 10-16.

45. Weast, J. (2008, August). Creating shared leadership that works. School Administrator, 65(7), p.38.

46. Zhao, Y., \& Frank, K.A. (2003). Factors affecting technology users in school: An ecological perspective. American Educational Research Journal, 40, 807-840. 


\section{$\underline{\text { NOTES }}$}

